increases the wool yield from an average of $8.4 \mathrm{lb}$. to an average of $11.625 \mathrm{lb}$. It also increases resistance to prussic acid, and may be of value in reducing 'geilsiekte', a poisoning that arises from ingestion of certain plants in which a cyanogenetic glycoside is present. The report, in two parts, is admirably produced and illustrated (Government Printer, Pretoria, 20s.)

\section{Health of the Navy during I93I}

The statistical report of the health of the Navy for the year 1931, by the Medical Director General, ViceAdm. R. St. G. S. Bond, states that there was an increase in the incidence of disease as compared with the five years' average and with 1930 , largely due to an increase in influenza of nearly 2,000 cases. Malaria and venereal diseases declined markedly. Nine cases of undulant fever were reported from the Mediterranean station. It is remarked that undulant fever has increased among Maltese civilians, and in conse. quence a Government commission is considering the possibility of introducing the compulsory pasteurisation of goats' milk at a central distributing station and the prohibition of retail sales as at present transacted by driving the goats from door to door. Only five cases of enteric fevers were reported.

\section{Index Veterinarius}

THE first number of the Index Veterinarius, covering the indexing done at the Imperial Bureau of Animal Health during the first quarter of 1933, will be issued during the summer. This work will be a complete index to publications relating to veterinary research and public health administration and education. An annual volume, which will be in crown quarto size, will run to about 1,600 pages; and a number, consisting of about 400 pages, will be issued each quarter. About 10,000 references will be indexed each year, each reference being suitably cross-indexed alphabetically both under the names of authors and subjects and, with cross-indexing, there will be about 50,000 insertions in a volume. The price of the Index is $£ 4$ a volume (four quarterly issues) including postage. Orders should be sent to the Imperial Bureau of Animal Health, Veterinary Laboratory, Ministry of Agriculture and Fisheries, Weybridge, Surrey, England.

\section{Library of the London School of Hygiene and Tropical Medicine}

THE London School of Hygiene and Tropical Medicine has issued a second edition, compiled by the librarian, Mr. Cyril Barnard, of the "Hand List of Periodicals" contained in the Library on January 31, I933 (Wightman and Co., Ltd., Dugdale Street, S.E.5. 1s. 3d.). The arrangement of entries is alphabetical by titles, according to the rules adopted in the "World List", and the "World List" numbers are added to all the periodicals which are contained in that publication. An index of societies and institutions is appended, with the number in the list of the periodicals attached to each entry.

\section{Service for the Blind}

THE Report of the Librarian of Congress for 1932 witnesses to the effort being made to meet the needs of blind readers in the United States. The number of blind readers who borrowed embossed material during the year was 3,225 , and the library collection now contains 24,824 items. An attempt is made to furnish blind readers with the best literature in all fields of knowledge which, on account of the financially unprofitable nature of embossed printing, they have hitherto been unable to obtain. The type of book suitable for transcription is limited, since works the value or attractiveness of which rests largely upon illustrations, are barred. But within the limits, the special accessions, which began with Woodrow Wilson's "George Washington" and contain, on the scientific side, works by Jeans, Maeterlinck, Arthur Keith, Harvey-Gibson, Russell and others, make a notable list of 126 works in Braille and 31 in Moon type.

\section{Preservation of Metallic Objects in Museums}

Museum curators are often faced and baffled by the problem of dealing with objects of metal which have deteriorated through exposure, and tend to go from bad to worse when placed on exhibition. They will find a very useful guide to the most satisfactory methods of treatment in a paper by Dr. Alexander Scott in the Museums Journal of April (p. 4), where, in addition, hints are given for making brittle substances flexible, for using hydrogen peroxide in restoring degraded flake white to its original colour, for treating foxed prints and removing oil stains.

\section{Collection and Preservation of Animals}

The National Museum of Canada has just published a work on "Methods of Collecting and Preserving Vertebrate Animals", which ought to prove useful to travellers and holiday-makers who wish to add to their pleasures that of contributing to the knowledge of their country's fauna (Nat. Mus. Canada, Bulletin No. 69, Biological Series, No. 18, Ottawa, 1932). While less compact and less convenient in size for carrying than the well-known British Museum collectors' handbooks, Mr. R. M. Anderson's book has the advantage of being more thorough in its treatment and of containing a large number of illustrations showing steps in the progress of skinning. In separate chapters it deals with the collecting and skinning of mammals, birds, reptiles, amphibians and fishes, and a special chapter describes the collecting of skeletons. There are 135 pages of descriptive matter, a very complete index of 5 pages, 46 illustrations, and the cost is only 25 cents.

\section{The late Lieut.-Col. A. W. Alcock}

IN connexion with the obituary notice of the late Lieut.-Col. A. W. Alcock in NAture of April 22, Dr. B. Prashad, of the Zoological Survey of India, states that Col. Alcock's association with the Indian Museum began at the end of the survey season of 1888-89, for with the beginning of the south-west 